\title{
Variability in treatment advice for elderly patients with aortic stenosis: a nationwide survey in the Netherlands
}

\author{
B J Bouma, J H P van der Meulen, R B A van den Brink, A E R Arnold, A Smidts, \\ L H Teunter, K I Lie, J G P Tijssen
}

\begin{abstract}
Objective-To determine how the decisions of Dutch cardiologists on surgical treatment for aortic stenosis were influenced by the patient's age, cardiac signs and symptoms, and comorbidity; and to identify groups of cardiologists whose responses to these clinical characteristics were similar.

Design-A questionnaire was produced asking cardiologists to indicate on a six point scale whether they would advise cardiac surgery for each of 32 case vignettes describing 10 clinical characteristics.

Setting-Nationwide postal survey among all 530 cardiologists in the Netherlands.

Results- $52 \%$ of the cardiologists responded. There was wide variability in the cardiologists' advice for the individual case vignettes. Six groups of cardiologists explained $60 \%$ of the variance. The age of the patient was most important for $41 \%$ of the cardiologists; among these, $50 \%$ had a high and $50 \%$ a low inclination to advise surgery. A further $24 \%$ were influenced equally by the patient's age and by the severity of the aortic stenosis and its effect on left ventricular function; among these, $62 \%$ had a high and $38 \%$ a low inclination to advise surgery. Finally, $23 \%$ of the cardiologists were mainly influenced by the left ventricular function and $12 \%$ by the aortic valve area. The presence of comorbidity always played a minor role.

Conclusions-There were systematic differences among groups of cardiologists in their inclination to advise aortic valve replacement for elderly patients, as well as in the way their advice was influenced by the patients' characteristics. These results indicate the need for prospective studies to identify the best treatment for elderly patients according to their clinical profile.

(Heart 2001;85:196-201)
\end{abstract}

Keywords: aortic stenosis; aortic valve replacement; elderly patients; clinical decision making

There are clear clinical guidelines for the treatment of young and middle aged patients with aortic stenosis. ${ }^{1}$ These guidelines indicate that in general patients with symptomatic stenosis should undergo surgery and aortic valve replacement. Treatment decisions for elderly patients are more difficult, as the patient's age and any concomitant diseases tend to increase the harmful effects and decrease the benefit of aortic valve replacement. The prevalence of aortic stenosis $\left(\leqslant 1.2 \mathrm{~cm}^{2}\right)$ in the general population increases with age from $2.5 \%$ at 75 years to $8.1 \%$ at 85 years. $^{2}$ This implies that with the aging of the population cardiologists will see more and more of these patients in the future.

The dilemma for elderly patients may be illustrated by the following clinical example. A 72 year old man is seen by a cardiologist at the outpatient clinic. He has symptoms of angina and dyspnoea class III according to the New York Heart Association (NYHA) classification. The patient also has impaired renal function (serum creatinine $250 \mu \mathrm{mol} / \mathrm{l}$ ) and has had a stroke, resulting in moderate residual paresis. Pulmonary function is normal. There is clinical evidence of left ventricular failure. Doppler echocardiography reveals an aortic valve area of $0.6 \mathrm{~cm}^{2}$, and the left ventricular ejection fraction is $20 \%$. A coronary angiogram is normal. Should this patient undergo aortic valve replacement? To answer this dilemma, the cardiologist has to balance the mortality and morbidity associated with the aortic valve replacement against the expected gain in the duration and quality of the patient's life.

There is hardly any information about the outcome of aortic valve replacement in elderly people. Most studies have been performed in selected young and middle aged patients. ${ }^{3-7}$ Information about the outcome of medical treatment dates back to the presurgical and precatheterisation era, and relates almost exclusively to younger patients ${ }^{8}$; more recent studies have involved few elderly patients and have reported on combined end points (for example, a combination of death and cardiac surgery), which makes their results difficult to interpret. ${ }^{9-12}$

A particular problem is that elderly patients often have concomitant diseases. The selective nature of the available evidence makes it impossible to untangle the effects of age and comorbidity on the vitality of a patient in general, and the advisability of surgical treatment in particular. We therefore performed a nationwide postal survey to investigate the advice that Dutch cardiologists give to elderly patients with aortic stenosis. We used techniques that are used to investigate consumers' decisions in marketing research. ${ }^{13}$ In this way, we were able to estimate the extent to which the advice given 
Table 1 Background characteristics of cardiologists according to response status

\begin{tabular}{lllll}
\hline & $\begin{array}{l}\text { Responders } \\
(n=275)\end{array}$ & $\begin{array}{l}\text { Non-responders } \\
(n=255)\end{array}$ & All (n=530) & p Value $^{*}$ \\
\hline Age (years) $\dagger$ & $45.5(7.7)$ & $48(6.4) \ddagger$ & $47(7.4)$ & 0.00 \\
Men & $92 \%$ & $92 \%$ & $92 \%$ & 0.9 \\
Year of accreditation $\dagger$ & $1982(6.4)$ & $1982(7.0) \ddagger$ & $1982(6.8)$ & 0.7 \\
$\begin{array}{l}\text { University hospital } \\
\text { Hospital with cardiac }\end{array}$ & $23 \%$ & $17 \%$ & $20 \%$ & 0.09 \\
$\quad 30 \%$ & $25 \%$ & $28 \%$ & 0.19 \\
$\quad \begin{array}{l}\text { surgery } \\
\text { Ward size > }>\text { beds }\end{array}$ & $33 \%$ & $43 \% §$ & $37 \%$ & 0.02 \\
\hline
\end{tabular}

${ }^{\star} t$ Test or $\chi^{2}$ test for $2 \times 2$ table.

†Mean (SD).

$\ddagger 52$ missing.

$\$ 13$ missing. disease (none or first second forced expired ventilation below $60 \%$ of predicted), and renal disease (none or serum creatinine $250 \mu \mathrm{mol} / \mathrm{l}$ ).

EXPERIMENTAL DESIGN

We designed 32 case vignettes in which the levels of these 10 clinical characteristics were varied according to an orthogonal factorial design. ${ }^{15}$ This design made it possible to estimate the influence of each clinical characteristic on the cardiologist's decision to advise valve replacement or not independently of the nine others. For each case, the cardiologists were asked to indicate on a six point scale, ranging from "certainly no" to "certainly yes", whether they would advise surgery. The cases were described on separate sheets of paper and presented to each cardiologist in one of eight different random orders (see the appendix for an example of a case vignette).

We added four extra case vignettes ("hold out profiles") to the questionnaire, which were used to evaluate whether the observed advice given for these four cases could be predicted using the statistical model derived from the other 32 .

\section{STATISTICAL MODEL}

Latent class linear regression analysis was used to analyse the responses of the cardiologists to the case vignettes. ${ }^{16-19}$ This is a technique developed in marketing research, and the technical details of its present application are described in an accompanying paper (A Smidts, unpublished data). Briefly, latent class regression estimates a number of regression equations in which the advice score of the cardiologists (on the six point scale) is the dependent variable, and dummy variables represent the levels of the clinical characteristics as independent variables. Each regression equadisease), neurological disease (none or history of stroke with moderate paresis), pulmonary

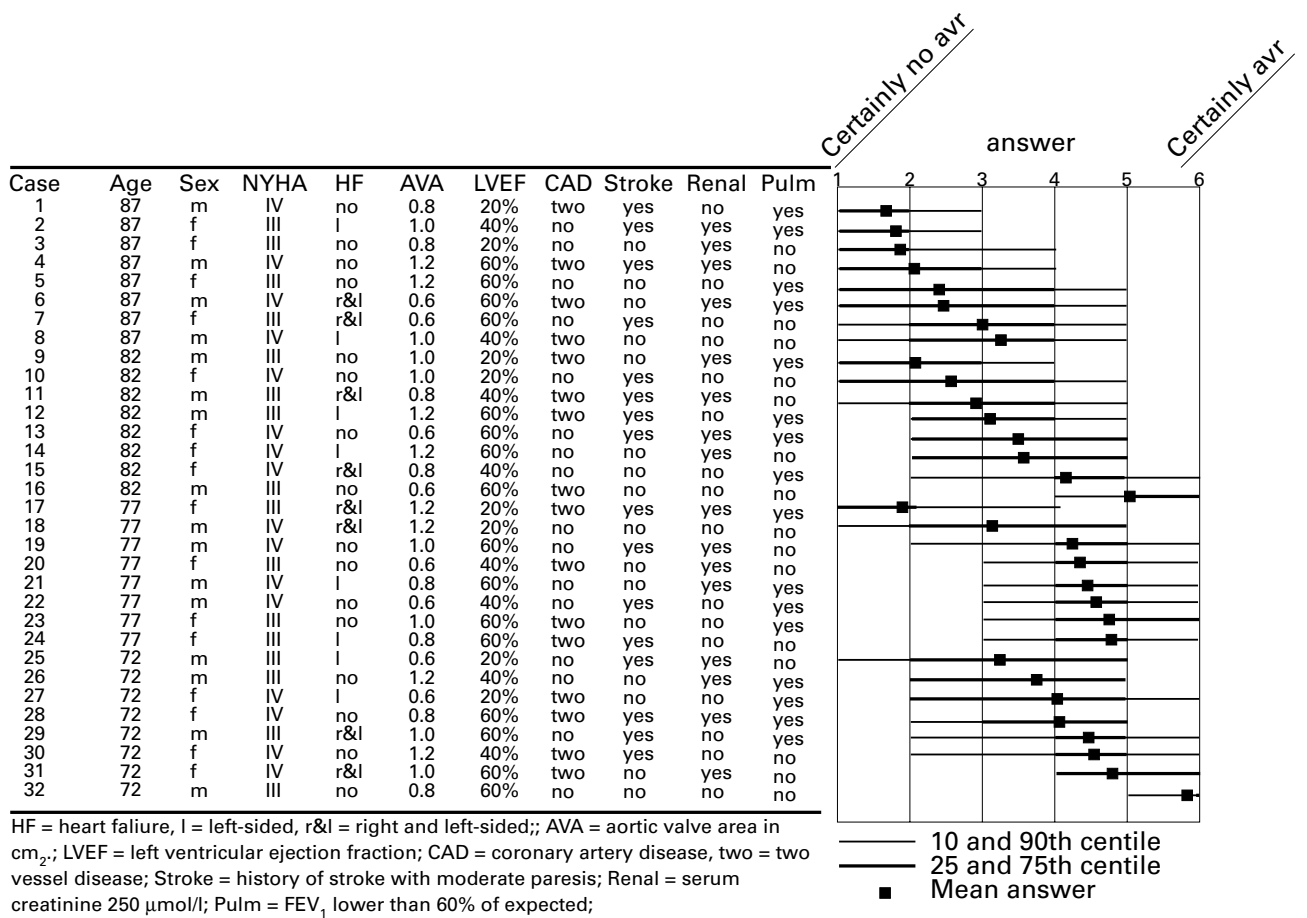

Figure 1 Treatment advice of 275 Dutch cardiologists for 32 written case vignettes. 
tion represents the results for a "latent class" of cardiologists who responded to the clinical characteristics in a similar way. The classification of the cardiologists, as well as the number of classes that optimally explains the heterogeneity in the responses, were determined by statistical criteria. The coefficients of the regression equations can be used to calculate within a particular group (that is, class) of cardiologists the overall mean of the advice score as well as the mean advice score for each level of the clinical characteristics.

\section{Results}

Of the 530 Dutch cardiologists who were sent a questionnaire, 275 (52\%) responded. Background characteristics of all responding and non-responding cardiologists are presented in table 1 . There was a tendency for responding cardiologists to be younger, to be working in a university hospital more often, and to be responsible for smaller wards.

\section{VARIABILITY AMONG CARDIOLOGISTS}

Figure 1 shows the wide variability in the advice scores of all 275 responding cardiologists for the 32 case vignettes. This variability is illustrated by the advice given for the clinical example presented in the introduction (case number 25), where it was found that 24 cardiologists ( $9 \%$ of the 275 responders) indicated that they certainly would advise surgery (advice score of 6), whereas 39 (14\%) indicated that they certainly would not (advice score of 1 ).

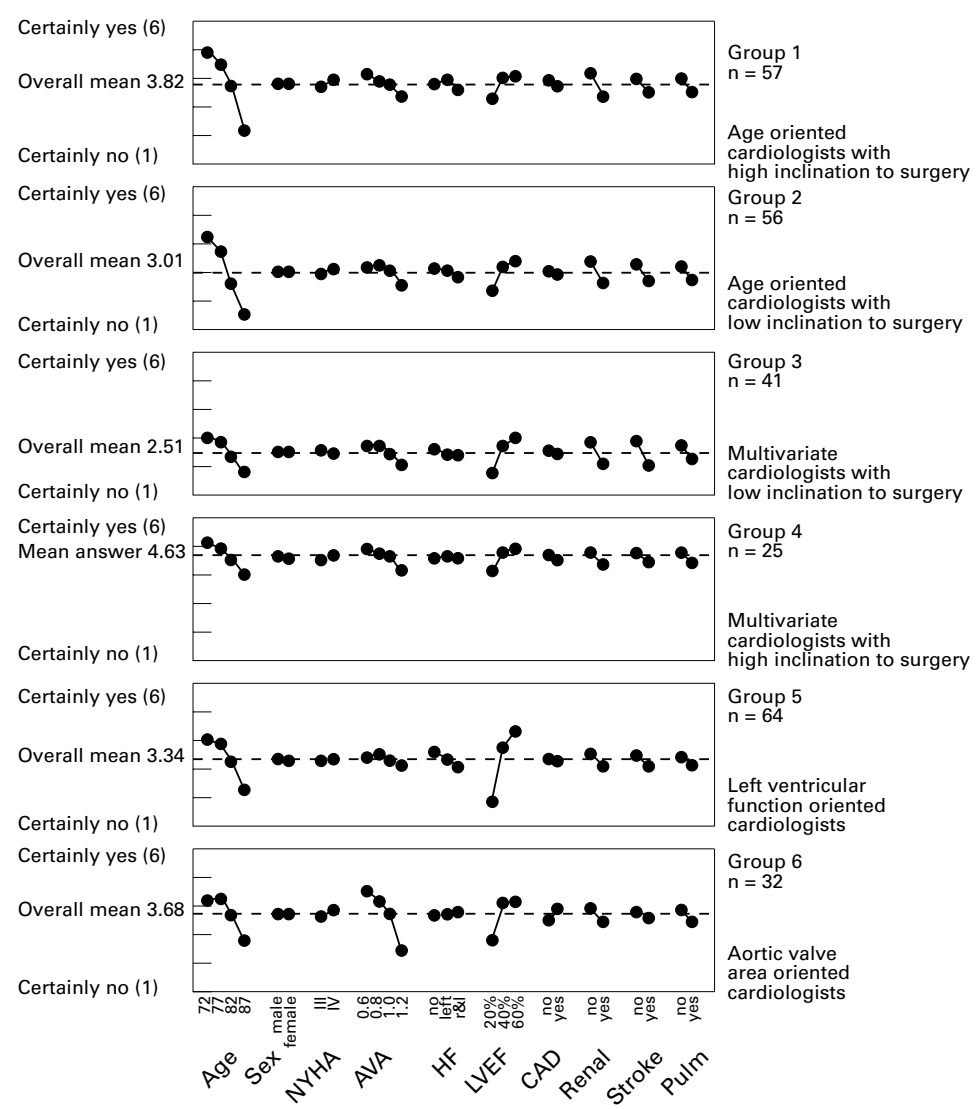

Figure 2 Mean advice score for six groups of cardiologists for each level of the clinical characteristics as well as the overall mean advice score. See text for explanation.
The interquartile range (that is, the difference between the 75 th and the 25 th centiles) was four points on the six point scale. A similarly large interquartile range could be observed in the advice for eight other vignettes (case numbers $5,6,10,13,14,18,26$, and 27).

The advice for some of the other case vignettes was less heterogeneous. For example, most cardiologists (more than $90 \%$ responded with an advice score of 1,2 , or 3 ) would not advise surgery for three 87 year old patients who had an impaired left ventricular function with at least one comorbid condition (cases 1, 2 , and 3), or for a 77 year old woman with impaired left ventricular function, moderate aortic stenosis, and three comorbid conditions (case 17). Also, most cardiologists agreed (more than $90 \%$ responded with an advice score of 4,5 , or 6 ) that surgery should be advised for those patients who had a severe aortic stenosis (aortic valve area $\leqslant 1.0 \mathrm{~cm}^{2}$ ) with good left ventricular function and no comorbid conditions (cases 16, 31, and 32).

GROUPS OF CARDIOLOGISTS

The latent class regression analysis identified six different groups of cardiologists whowithin each group - came up with similar decisions as to the advisability of aortic valve replacement. This analysis explained $60 \%$ of the variance in the cardiologists' advice scores. Figure 2 shows the overall group means of the advice scores (representing the average inclination to advise surgery for the 32 case vignettes), in addition to the mean advice score for each level of the 10 clinical characteristics (representing the extent to which the cardiologists responded to each characteristic). It shows that cardiologists in group 1 and 2 (making up 41\% of all responding cardiologists) were predominantly influenced by age (absolute differences between the mean advice score for a 72 year old and an 87 year old patient were 2.7 and 2.8, respectively). For these cardiologists the other clinical variables played a less important role (absolute difference between highest and lowest advice score always less than 1.0). Accordingly, cardiologists in group 1 and 2 could be considered "age oriented decision makers". However, the overall mean of the advice scores was considerably higher for group 1 than for group 2, which indicates that group 1 had on average a greater inclination to advise surgery than group 2. This also corresponds to the observation that cardiologists in group 1 advised surgery on average for $65 \%$ of the 32 case vignettes (advice scores ranging from 4 to 6 ), and those in group 2 for only for $46 \%$.

The cardiologists in group 3 and 4 (making up $24 \%$ ) were influenced in a similar way by age, aortic valve area, and ejection fraction, and also-but much less strongly - by the presence of renal, neurological, and pulmonary disease. These groups were similar in being "multivariate decision makers", but differed strongly with respect to their inclination to advise surgery. The cardiologists in group 3 on average advised surgery for $32 \%$ of the case vignettes, whereas those in group 4 recommended it in $86 \%$. 
Table 2 Background characteristics of the cardiologists according to decision making behaviour

\begin{tabular}{|c|c|c|c|c|c|c|c|c|}
\hline \multirow[b]{2}{*}{ Inclination for surgery: } & \multicolumn{2}{|c|}{ Age oriented } & \multicolumn{2}{|c|}{ Multivariate } & \multirow{3}{*}{$\begin{array}{l}\text { LV function } \\
\text { oriented } \\
5 \\
(n=64)\end{array}$} & \multirow{3}{*}{$\begin{array}{l}\text { Ao valve area } \\
\text { oriented } \\
6 \\
(n=32)\end{array}$} & \multirow{3}{*}{$\begin{array}{l}\text { All } \\
(n=275)\end{array}$} & \multirow[b]{3}{*}{ p Value } \\
\hline & High & Low & High & Low & & & & \\
\hline Group: & $\begin{array}{l}1 \\
(n=57)\end{array}$ & $\begin{array}{l}2 \\
(n=56)\end{array}$ & $\begin{array}{l}3 \\
(n=41)\end{array}$ & $\begin{array}{l}4 \\
(n=25)\end{array}$ & & & & \\
\hline Mean age (years) & 44 & 44 & 46 & 44 & 48 & 45 & 45.5 & 0.01 \\
\hline Men & $95 \%$ & $86 \%$ & $100 \%$ & $90 \%$ & $92 \%$ & $91 \%$ & $92 \%$ & 0.33 \\
\hline Trained in university hospital & $84 \%$ & $75 \%$ & $71 \%$ & $88 \%$ & $80 \%$ & $88 \%$ & $77 \%$ & 0.32 \\
\hline Year of accreditation & 1984 & 1984 & 1981 & 1983 & 1980 & 1984 & 1982 & 0.02 \\
\hline University hospital & $23 \%$ & $21 \%$ & $34 \%$ & $16 \%$ & $14 \%$ & $37 \%$ & $23 \%$ & 0.07 \\
\hline Hospital with cardiac surgery & $32 \%$ & $30 \%$ & $41 \%$ & $24 \%$ & $17 \%$ & $44 \%$ & $30 \%$ & 0.05 \\
\hline Ward size $>40$ beds & $30 \%$ & $34 \%$ & $34 \%$ & $40 \%$ & $33 \%$ & $28 \%$ & $33 \%$ & 0.95 \\
\hline
\end{tabular}

${ }^{\star}$ Analysis of variance or $\chi^{2}$ test for contingency table.

Ao, aortic; LV, left ventricular.

The cardiologists in group $5(23 \%)$ based their advice on the left ventricular function and to some extent also on the age of the cases. These "left ventricular function oriented decision makers" advised surgery in $58 \%$ of the 32 case vignettes.

The cardiologists in group $6(12 \%)$ were most strongly influenced by the aortic valve area, although age and left ventricular function also played a role. These "valve area oriented decision makers" recommended surgery in $61 \%$ of the case vignettes.

RELATION TO BACKGROUND CHARACTERISTICS The age and year of graduation of the cardiologists, as well as the presence of facilities for cardiac surgery, differed significantly among the six groups of cardiologists (table 2). The age oriented cardiologists (groups 1 and 2) seemed to be slightly younger and to have been accredited as cardiologists more recently, while the left ventricular function oriented cardiologists (group 5) seemed to be older and to have been accredited longer ago than the others. The multivariate cardiologists with a low inclination for surgery (group 4), as well the valve area oriented cardiologists (group 6), seemed more often to be affiliated to university hospitals and less often to hospitals without facilities for cardiac surgery, whereas the opposite was the case for the left ventricular function oriented cardiologists (group 5).

MODEL EVALUATION

For each cardiologist we compared the observed advice scores for the four extra case vignettes (hold out profiles) with the advice score predicted by the latent class regression model based on the original 32 cases. The actual and predicted advice scores corresponded well, with a difference of less than one point on the six point scale in $88 \%$ of the cases. If, for each case, the advice was dichotomised into advice for or against surgery (advice score of 4 or more or 3 or less, respectively), the observed and predicted advice agreed also in $88 \%$ of the cases.

\section{Discussion}

Our nationwide survey among Dutch cardiologists revealed wide variability in the advice given in a series of paper case vignettes describing elderly patients with aortic stenosis. Much of this variability could be explained by distinguishing six groups of cardiologists. We detected four main practice styles: $41 \%$ of the cardiologists were age oriented decision makers, $24 \%$ were multivariate decision makers (influenced equally by age and by the severity of the stenosis and the impairment of left ventricular function), $23 \%$ were left ventricular function oriented decision makers, and 12\% were valve area oriented decision makers. The age oriented decision maker group and the multivariate decision maker group could each be broken down into a group with a high and a low average inclination to advise surgery. A comparison of the background characteristics among these six groups of cardiologists showed small differences in age, time since accreditation, and hospital type.

PRACTICE STYLES

Age was the major determinant of the advice score of $41 \%$ of the cardiologists. The epidemiological evidence to support this dominant influence of age is poor. Studies among patients of 70 years and older showed that the increasing effect of age on surgical mortality could be explained for the greater part by other clinical characteristics and comorbid conditions. ${ }^{20-23}$ The patients included in these prognostic studies, however, were highly selected and the validity of the results for unselected patients is debatable.

The $23 \%$ of the cardiologists who, in addition to the patient's age, were mainly influenced by left ventricular function, advised strongly against surgery in patients with a left ventricular ejection fraction of only $20 \%$. This behaviour fits with observations that impaired left ventricular function is associated with increased surgical mortality and morbidity, ${ }^{21-24}$ although it is also associated with a very poor prognosis after conservative treatment. ${ }^{8-12}$ On the other hand, there is also evidence that left ventricular function can improve considerably after surgical treatment, ${ }^{25} 26$ and that in particular the prognosis of patients with impaired left ventricular function improves after aortic valve replacement. ${ }^{14}$

The $12 \%$ of the cardiologists who, in addition to the patient's age, were mainly influenced by aortic valve area advised against surgery for patients with a valve area of $1.2 \mathrm{~cm}^{2}$, whether severe cardiac symptoms were present or not. This attitude is questionable as a study examining the outcome of patients with moderate aortic stenosis showed that the over- 
all mortality rate in patients who already have symptoms approaches the outcome in patients with severe aortic stenosis. ${ }^{9}$

The cardiologists' advice scores were hardly affected by whether or not there was coronary artery disease, although a surgical procedure allows replacement of the aortic valve as well as coronary artery bypass grafting. This suggests that the cardiologists believe that the increased benefits of such a combined surgical procedure do not outweigh the twofold rise in surgical mortality that has been shown to be associated with it. ${ }^{21}$

The average inclination to advise surgical treatment varied considerably between groups. One group of cardiologists advised surgery on average in $32 \%$ of the case vignettes (group 3 in table 2), whereas another advised surgery in $86 \%$ (group 4). A comparison of the background characteristics of these conservative and interventionist cardiologists suggests that the former more often work in university hospitals and in those with facilities for cardiac surgery. This suggests that the interventionist cardiologists more often have to refer patients with aortic stenosis to a tertiary centre, where further evaluation of these patients is performed and where the final decision to operate or not is made. It is therefore not unlikely that the more "aggressive" advice given by these cardiologists reflects this extra tier in the decision making process.

COMORBIDITY

We found that comorbidity hardly affected the treatment advice of the cardiologists. This is remarkable as the few studies available on this matter have shown that the impact of comorbidity on the outcome of surgery is considerable. A study of patients who underwent a coronary artery bypass procedure found, for example, that those who had had a previous stroke had a ninefold greater risk of stroke after surgery than those who had not. ${ }^{27}$ A study of patients more than 80 years old indicated that mortality in the first five years after cardiac surgery was 2.6 times higher in patients with impaired renal function and 1.9 times higher in patients with chronic lung disease. ${ }^{28}$

The American College of Cardiology/ American Heart Association guidelines for the management of patients with valvar heart disease, which were published in 1998 after we had finished our survey, indicate that valve replacement is technically possible at any age, but that severe comorbid conditions make cardiac surgery inappropriate. ${ }^{1}$ In other words, they indicate that the biological age of the patient should play a more important role than chronological age in the decision making process relating to valve surgery in elderly patients, without giving clear guidance on how to implement this in practice.

In our series of 32 case vignettes, the prevalence of comorbidity was independent of age, whereas in clinical practice concomitant morbidity is indisputably more common and usually more severe in older patients. One possible explanation for the importance of age in our study, and the relative insignificance of comorbidity, is that it is difficult if not impossible for cardiologists to distinguish the effects of age and comorbidity. The cardiologists may be using age as the sole measure of a patient's prognosis, which also incorporates the age related frequency and severity of comorbid conditions. Although this strategy might be legitimate in general, it clearly denies older patients without comorbid conditions access to beneficial surgical treatment.

METHODOLOGICAL CONSIDERATIONS

The survey was sent to all cardiologists who were members of the Dutch Society of Cardiology. The membership list includes more than $95 \%$ of all Dutch cardiologists. The non-responding cardiologists appeared to be slightly older, less often working in university hospitals, and more often responsible for larger wards. Because these differences were small, we feel that our results are representative of all cardiologists in the Netherlands.

We used the cardiologists' responses to a series of carefully designed paper case vignettes. Major advantages of this approach were that, apart from its low costs, it allowed us to study the treatment advice of every cardiologist for the same series of cases. The very recent introduction of a user friendly software package that we used to perform the latent class regression analysis might further stimulate the application in clinical medicine of techniques primarily developed for marketing research. ${ }^{19}$

One might question the validity of using paper case vignettes, first because the vignettes offer only a simplified description of the patients' clinical profile, and second because the respondents know that their advice will have no actual consequences. We found, however, that the observed advice scores for the four extra case vignettes (the hold out profiles) were in close agreement with scores predicted by the latent class model on the basis of the original 32 cases, which shows the internal consistency of the cardiologists' decision making behaviour. Furthermore, we also compared the response to the case vignettes given by cardiologists from three university hospitals with observed practice in a consecutive series of 147 actual cases in these hospitals (BJ Bouma, unpublished data). The responses to the case vignettes and the observations of actual clinical practice produced remarkably similar results in respect of the influence of the clinical characteristics on the decision making process.

\section{CONCLUSIONS}

We found systematic differences among groups of cardiologists in their inclination to advise surgical treatment for elderly patients with symptomatic aortic stenosis, as well as in the way their advice was influenced by the clinical characteristics of these patients. Given that randomised controlled trials of the effectiveness of surgical treatment among elderly patients with aortic stenosis are unlikely to happen in the near future, there is a clear need for prospective observational studies that include medically and surgically treated elderly patients followed up after the identification of 
aortic stenosis. These studies should use accurate measures of cardiac signs, symptoms, and comorbid conditions.

We thank Jack Dowie and Colin Sanderson, London School of Hygiene and Tropical Medicine, for their useful comments.

\section{Appendix: Example of a case description used in the questionnaire (case 25 in fig 1)}

You see a 72 year old man at the outpatient clinic. The medical history shows that he has cardiac symptoms of class III according to the New York Heart Association criteria.

The medical history also shows the following:

The patient has had a stroke with a slight remaining paresis. Renal function is impaired (serum creatinine $250 \mu \mathrm{mol} / \mathrm{l}$ ). Pulmonary function is normal.

On physical examination, you find a normal blood pressure and pulse. On auscultation of the heart, you detect a murmur with a maximum at $2 \mathrm{R}$, radiating to the carotid arteries. On auscultation of the lungs, you detect crepitations.

Doppler echocardiography reveals important aortic stenosis. The aortic valve area is estimated to be $\mathbf{0 . 6} \mathbf{~ c m}^{2}$. The left ventricular function ejection fraction is $\mathbf{2 0 \%}$.

Afterwards the patient undergoes cardiac catheterisation. Coronary angiography shows no coronary artery disease.

\section{Question}

Would you advise this patient surgical treatment?

$\square$ Certainly yes (6)

$\square$ Probably yes (5)

$\square$ Possibly yes (4)

$\square$ Possibly no (3)

$\square$ Probably no (2)

$\square$ Certainly no (1)

1 Bonow RO, Carabello B, de Leon AC, et al. ACC/AHA guidelines for the management of patients with valvular heart disease: a report of the American College of Cardiology/American Heart Association task force on practice guidelines (committee on management of patients with valvular heart disease). $\mathcal{F}$ Am Coll Cardiol 1998;32:1486-588.

2 Lindroos M, Kupari M, Heikkila J, et al. Prevalence of aortic valve abnormalities in the elderly: an echocardiographic tic valve abnormalities in the elderly: an echocardiographic
study of a random population sample. $₹ \mathrm{Am}$ Coll Cardiol study of a random
3 Verheul HA, van den Brink RBA, Bouma BJ, et al. Analysis of risk factors for excess mortality after aortic valve of risk factors for excess mortality after ao

4 Lund O. Preoperative risk evaluation and stratification of long-term survival after valve replacement for aortic stenosis. Reasons for earlier operative intervention. Circulation 1990;82:124-39.

5 Levinson JR, Akins CW, Buckley MJ, et al. Octogenarians with aortic stenosis; outcome after aortic valve replacement. Circulation 1989;80(suppl 1):49-56.

6 Galloway AC, Colvin SB, Grossi EA, et al. Ten-year experience with aortic valve replacement in 482 patients 70 years of age or older: operative risk and long-term results. Ann Thorac Surg 1990;49:84-93.

7 Olsson M, Granström L, Lindblom D, et al. Aortic valve replacement in octogenarians with aortic stenosis: a case-control study. $\mathcal{F}$ Am Coll Cardiol 1992;20:1512-16.

8 Ross J, Braunwald E. Aortic stenosis. Circulation 1968; 38(suppl V):V61-7.

9 Kennedy KD, Nishimura RA, Holme DR, et al. Natural history of moderate aortic stenosis. F Am Coll Cardiol 1991;17: 313-19.

10 Pellikka PA, Nishimura RA, Bailey KR, et al. The natural history of adults with asymptomatic, hemodynamically significant aortic stenosis. F Am Coll Cardiol 1990;15:101217

11 Horstkotte D, Loogen F. The natural history of aortic valve stenosis. Eur Heart f 1988;9(suppl E):57-64

12 Otto CM, Mickel MC, Kennedy JW, et al. Three-year outcome after balloon aortic valvuloplasty. Insights into prognosis of valvular aortic stenosis. Circulation 1994;89. $642-50$.

13 Wighton RS. Use of linear models to analyse physicians decisions. Med Decis Making 1988;8:241-52.

14 Bouma BJ, van den Brink RBA, van der Meulen JHP, et al. To operate or not upon elderly patients with aortic stenosis; the decision and its consequences. Heart 1999;82:143-8.

15 Addelman S. Orthogonal main-effect plans for asymmetrical factorial experiments. Technometrics 1962;4:21-46.

16 DeSarbo WS, Wedel M, Vriens $M$, et al. Latent class metric conjoint analysis. Marketing Letters 1992:33;273-88.

17 Vriens, M, Wedel M, Wilms T. Metric conjoint segmentation methods: a Monte Carlo comparison. Fournal of Marketing Research 1996;18:73-85.

18 Wedel M, DeSarbo WS. A mixture likelihood approach for generalized linear models, fournal of Classification 1995;12: $21-55$.

19 Wedel M. GLIMMIX. ProGramma software, Groningen, Netherlands, 1998 (http://www.gamma.rug.nl)

20 Wong JB, Salem DN, Pauker SG. Occasional notes. You're never too old. Too old for what? $N$ Engl $f \mathrm{Med}$ 1993;328:971-5.

21 Aranki SF, Rizzo RJ, Couper GS, et al. Aortic valve replacement in the elderly; effect of gender and coronary artery disease on operative mortality. Circulation 1993;88(part 2): $17-23$.

22 Strauman E, Kiowski W, Langer I, et al. Aortic valve replacement in elderly patients with aortic stenosis. $\mathrm{Br}$ Heart f 1994;71:449-53.

23 Logeais Y, Langanay T, Roussin R, et al. Surgery for aortic stenosis in elderly patients; a study of surgical risk and predictive factors. Circulation 1994;90:2891-8.

24 Elayda MAA, Hall RJ, Reul RM, et al. Aortic valve replacement in patients 80 year and older. Operative risks and long-term results. Circulation 1993;88(part 2):11-16.

25 Brogan WC, Grayburn PA, Lange RA, Hillis LD. Prognosis after valve replacement in patients with severe aortic stenosis and a low transvalvular pressure gradient. $\mathcal{f} \mathrm{Am}$ Coll Cardiol 1993;21:1657-60.

26 Morris JJ, Schaff HV, Mullany CJ, et al. Determinants of survival and recovery of left ventricular function after aortic valve replacement. Ann Thorac Surg 1993;56:22-9.

27 McKhann GM, Goldsborough MA, Borowicz LM, et al. Predictors of stroke risk in coronary artery bypass patients. Ann Thorac Surg 1997;63:516-21.

28 Akins CW, Daggett WM, Vlahakes GJ, et al. Cardiac operations in patients 80 years old and older. Ann Thorac Surg 1997;64:606-14. 